\title{
Inter-Organ Relationships among Gut, Lung and Skin beyond the Pathogenesis of Allergies: Relevance to the Zang-Fu Theory in Chinese Medicine
}

\author{
Hiu Yu Cherie Leung, Pou Kuan Leong, Jihang Chen, Kam Ming Ko* \\ Division of Life Science, Hong Kong University of Science \& Technology, Hong Kong, China \\ Email: *bcrko@ust.hk
}

How to cite this paper: Leung, H.Y.C., Leong, P.K., Chen, J.H. and Ko, K.M. (2017) Inter-Organ Relationships among Gut, Lung and Skin beyond the Pathogenesis of Allergies: Relevance to the Zang-Fu Theory in Chinese Medicine. Chinese Medicine, 8, 73-81. https://doi.org/10.4236/cm.2017.83006

Received: June 29, 2017

Accepted: August 4, 2017

Published: August 7, 2017

Copyright (๑) 2017 by authors and Scientific Research Publishing Inc. This work is licensed under the Creative Commons Attribution International License (CC BY 4.0).

http://creativecommons.org/licenses/by/4.0/ (c) (i) Open Access

\begin{abstract}
Research on allergy has recently uncovered an apparent co-occurrence of allergies in skin and the lungs, a phenomenon that has been coined "atopic march". A positive correlation has been found between gut microbiota at birth and the development of asthma and skin eczema later in life. Chinese medicine has long described a functional relationship between the large intestine and the lungs, and between the lungs and skin. In this short article, we examined the evidence in support of these inter-organ physiological/pathological relationships. In addition to the clinical observation of the relationship between the composition of gut microbiota at birth and the development of asthma later in childhood, gut microorganisms have also been shown to exert a protective effect on bacteria-induced pneumonia in experimental animals. Genetic predisposition was also found to play an important role in the coexistence of certain diseases of lung and skin. Despite the fact that the mechanism(s) underlying the connection of immune systems between two organs (such as the large intestine and the lungs) is still not clearly understood, it is the first time to correlate the relationship among gut, lung and skin based on recent clinical studies in relation to the Zang-Fu Theory in Chinese medicine. Future investigation of the gut-lung and lung-skin axes in terms of physiological/pathological relationships may help to provide a greater understanding of the pathogenesis of allergies, possibly establishing relevance to the Zang-Fu Theory in Chinese medicine.
\end{abstract}

\section{Keywords}

Gut, Lung, Skin, Zang-Fu Theory 


\section{Introduction}

The development of a comprehensive theory of how the functions of organs are inter-connected and influence each other has become an area of increasing research interest in modern medicine; whereas a large body of evidence from observations and numerous clinical applications were accumulated over the thousands of years where Chinese medicine was practiced. Among the inter-organ functional networks recognized in the Zang-Fu Theory in Chinese medicine, two such physiological/pathological relationships are that involving the large intestine and the lungs, and that of the lungs and the skin. Based on research findings in modern medicine, mention has been made of the possibility of a gut-lung connection and, to a lesser extent, a lung and skin relationship in terms of physiological function and pathological conditions. This article seeks to examine the evidence in support of these inter-organ physiological/pathological relationships.

\section{Atopic March}

Recent research has uncovered an apparent co-occurrence of skin and lung allergies, in that atopic dermatitis in infancy tends to be followed by allergic rhinitis and asthma later in childhood [1]. This phenomenon was coined "atopic march" [1], which is currently an area of considerable research interest. In addition, a positive correlation between gut microbiota at birth (which is associated with the development of asthma) and skin eczema later in life has also been found [2] [3]. All these suggest possible functional interactions among gut, lungs and skin. The existence of such inter-organ relationships could be instrumental in leading to an understanding of the pathogenesis of allergies, and other diseases in relation to these organ systems.

\section{Functional Similarities between Gut, Lung and Skin}

Inner surfaces of the gut, lung and the outer surface of skin are all covered by epithelial cells, which have direct contact with exogenous substances, particularly pathogens and bacteria. Despite being the body's first line of defense against such pathogens, a well-defined microbial environment, or microbiota, is also essential for the optimal functioning of these organs. If the microbiota is altered or disrupted, health problems can arise [4].

The microbiota in the gut, which is the most densely populated with microorganisms among all surfaces of the human body, has been extensively studied. It has been noted that the taxonomic gene composition of gut microbes is highly variable between individuals, implying that a healthy gut microbiota is found in terms of function and not certain microbial species [5]. The upper part of the respiratory tract is easily colonized by pathogen and bacteria, whereas the lower part of the lungs is less populated by microorganisms, possibly due to the relatively unfavorable environment [6].

\subsection{Gut-Lung Functional Interrelationship}

According to Chinese medicine theory, visceral organs can be divided into 2 
categories, namely, Zang and Fu, wherein each Zang organ has its corresponding $\mathrm{Fu}$ organ(s). The Lung is such a Zang organ, and its Fu organ is the Large Intestine. The Zang-Fu Theory states that the Lung can be infiltrated by "evil" (i.e., pathogens) entering from the Large Intestine [7].

In modern medicine, it has been observed that some lung diseases are pathologically related to the gut. Chronic lung disorders such as asthma and cystic fibrosis have been shown to exhibit manifestations in the gastrointestinal tract, namely, shifts in the gut microbiota composition [6]. A strong correlation was found between childhood asthma and low diversity of gut microbiota during infancy. It should be noted that the microbiota diversity is restored as early as 12 months after birth, long before asthmatic symptoms arise, suggesting the existence of a time-frame window for the pathogenesis of asthma [3]. A similar correlation was observed experimentally in mice; following a reduction in the number and diversity of gut microorganisms by the administration of antibiotics at 3 weeks of age, adult mice showed exacerbated experimental allergic airway inflammation upon aero-allergen exposure [8]. Similarly, for children with cystic fibrosis, which is a genetic disorder that mainly affects the lungs, there is a large difference between their gut microbiota as compared to healthy children of the same age, with diminished levels of certain bacteria in affected children [9].

The connection between gut microbiota and lung health is further emphasized in a study by Schuijt et al. [10], in which mice were depleted of gut microbiota, and then infected with Streptococcus pneumoniae. A group of mice were then given a fecal microbiota transplant and compared with control mice in terms of parameters of inflammation and alveolar macrophage whole-genome responses. Results showed that fecal microbiota transplantation protected microbiota-depleted mice against pneumonia, as assessed by parameters relating to bacterial dissemination, inflammation, organ damage and mortality. Metabolic pathways within alveolar macrophages were significantly affected by the absence of gut microbiota, with reduced cellular responses to certain metabolites, such as lipoteichoic acid and lipopoly saccharide. Macrophages from microbiota-depleted mice also showed a reduced ability to kill bacteria (Streptococcus pneumoniae) by phagocytosis.

Taken together, these experimental results suggest a pathological inter-relationship between gut microbiota and lung diseases. It is thought that the gut affects the lung's immune system, but the mechanism is not well understood. A paper by Trompette et al. [11] found that the fatty acid moiety produced in the metabolism of dietary fibre, by gut microbiota, influences the severity of allergic inflammation in the airways. More research is still needed to further explore the mechanism underlying the effect of gut microbiota on pulmonary function and susceptibility to respiratory diseases.

\subsection{Lung-Skin Relationship}

The Zang-Fu Theory proposes that skin is functionally linked to the Lung, with the Lung playing a role in controlling the "gaps" or pores on the skin, thereby 
regulating sweating and body temperature, as well as the skin's immune system. According to Chinese medicine theory, if a patient manifests symptoms reflecting poor respiratory function, or insufficient Lung Qi (which refers to the physiological functioning of the Lung), foreign "evil" can easily invade the body by passing through it souter surface. If Lung Qi is at an optimal level, then the skin is glossy and the complexion shiny. In this connection, Houttuynia cordata Thunb is a commonly used herb for treating both pneumonia and skin eczema [12].

In modern medicine, an association between allergic diseases of the lungs and airways with those of the skin has been observed (see "atopic march"). However, this pathological inter-relationship can extend beyond allergies, i.e., including non-allergic diseases of these two organs.

However, it is important to first note that many pulmonary diseases, although sometimes exhibiting dermatological manifestations [13] [14], many of them also show symptoms elsewhere in the body. For example, lung cancer has a $1 \%$ to $12 \%$ likelihood of developing skin metastases, but the neoplasia may also invade other organs in the body [13]. Similarly, Mycobacterium tuberculosis can infect organs other than the lungs, including the skin, and cause lesions [14], displaying the possibility of relation between skin and lungs. But again, the tuberculosis bacterium can also invade other organs. Using only dermatological manifestations of non-allergic pulmonary diseases which have no high co-occurrence, especially in the case where it is not an exclusive manifestation, is not enough to form a convincing argument for a unique connection between skin and lungs.

One example of strong co-occurrence of lung and skin problems is high levels of airborne pollutants and lower skin health. Smoking and air pollution have long been known to affect the condition of the skin-for example, causing premature wrinkles, as evidenced by epidemiological studies. Huls et al. reported an association between nitrogen dioxide $\left(\mathrm{NO}_{2}\right)$ levels in the environment and the geometric mean number of cheek lentigines, or pigmented spots, commonly known as liver spots [15]. This association was observed in two different populations (Germany and China) in regions with similar UV exposures, and with individuals over 50 years of age [15]. In this regard, $\mathrm{NO}_{2}$ exposure has been known to impair lung function and increase the risk of lung cancer [16]. However, it should be noted that the increase in the incidence of cheek lentigines was fairly small when estimated on the basis of a per unit increase in $\mathrm{NO}_{2}$. Further studies are required to confirm these findings [17].

In another study, Vierkotter et al. (2010) showed that cigarette smoking and ambient soot levels promoted prominently visible signs of skin aging, including pigment spots and wrinkles [18]. With this finding, they demonstrated, for the first time, that airborne particulate matter was a factor in causing extrinsic skin aging [18].

\subsection{Co-Occurrence of Skin and Lung Issues in Certain Genotypes}

In the foregoing discussion, it has been shown that extrinsic factors, such as air 
pollutants and cigarette smoke, are associated with both skin wrinkling and a decline in lung function [18]. In this regard, a study from Vierkotter et al. showed that elderly women carrying certain matrix metalloproteinase (MMP) promotor variants exhibited a higher susceptibility to skin wrinkling and decreased lung function (as assessed by the ratio of forced expiratory volume to forced volume capacity) [19]. As such, not only did they demonstrate an association between skin wrinkling and obstruction of lung function, but also a common genetic predisposition to skin and lung disorders. MMP are a group of extracellular matrix (ECM) degrading enzymes. It has been suggested that the association of smoking with lung dysfunction and skin aging is due to such MMP-induced structural changes in ECM [19]. The specific MMP promoter variants identified are designated MMP-1 and MMP-3. Interestingly, MMP-1 promoter polymorphism also appear to increase susceptibility to colorectal cancer, according to two other studies, again implicating a possible linkage between lung and gut health [20] [21].

In research of allergic diseases, genetic and environmental factors have both been noted to strongly influence the development of atopic march [1]. The common genetic predisposition to lung and skin aging above suggests an association between lung and skin function that extends beyond those of allergic diseases. One study followed a group of infants who had acute severe bronchiolitis, and found that $50 \%$ of them developed dry skin or eczema within 12 months post-recovery from the bronchiolitis. [22]. Another study found that babies suffering from atopic dermatitis in their first 2 years of life had an increased risk of not only asthma, but other respiratory system-related diseases, as assessed by the incidence of acute otitis media (a middle ear infection), pneumonia and the use of antibiotics [23]. The association between atopic dermatitis and respiratory infections prevailed even after stratification for asthma.

\subsection{Gut-Skin Relationship}

The gut-skin relationship, which is not the main scope in this review, has been reported recently. In brief, O'Neill et al. have proposed a gut-skin relationship in regulating the physiological functions [24]. It has been suggested that the metabolites, hormones or neurotransmitters arising from gut microbiota may circulate in the blood and hence affect the physiological functions of the skin. Various diseases, such as inflammatory bowel disease, coeliac disease, rosacea, cutaneous paraneoplasia and Peutz-Jeghers syndrome, have shown manifestations in gut and skin, suggesting a possible pathological relationship between gut and skin. In support of this, the diversity of gut microbiota in the early life seems to possess an inverse relationship to the development of atopic eczema in the later life [25].

\section{Conclusions and Perspective}

In summary, there is a growing body of evidence supporting the presence of a gut-lung axis and a lung-skin axis, wherein one organ of the axis is functionally 
related to the other (Table 1). For the gut-lung axis, experimental evidence supports a relationship between gut microbiota composition and lung function (Figure 1). It has been suggested that the microbiota of the two organs communicate and somehow influence each other. As regards investigation, it is difficult to analyze microorganisms in the lower respiratory tract, and the techniques for growing "difficult-to-culture" gut bacteria remain to be optimized. It appears that gut microbiota can undergo changes during infancy, but becomes less sensitive to change in later stages of life [6].

For the lung-skin axis, the pathological relationship between the two organs is particularly prominent in regard to allergic diseases, as exemplified by the phenomenon of "atopic march" (Figure 1). Existing evidence indicates that a genetic factor may be involved in such an association of organ function. The presence of certain alleles is linked to a phenotype that is susceptible to allergic reactions in both the lungs and the skin.

Furthermore, evidence shows that it is possible that the functional relationship involving the lung-skin axis can go beyond allergies to include infectious diseases and aging. Allergic responses occurring in one organ can increase the risk of the other in developing non-allergic diseases, suggesting that a functional deficiency in one organ canimpair that of another. This linkage may also be a result of a genetic predisposition, wherein an individual of a certain genotype would have diminished function in both the lungs and skin.

The mechanism determining the functional connection between organs is yet to be identified. Conceivably, it may be related to the connectivity of the immune system by cross-talk between mucosal epithelial cell layers in different

Table 1. Summary of gut-skin and skin-lung relationships.

\begin{tabular}{|c|c|}
\hline Recent findings on Gut-skin and Skin-lung relationships & References \\
\hline \multicolumn{2}{|l|}{ Gut-lung relationship } \\
\hline $\begin{array}{l}\text { The degree of diversity in gut microbiota at birth negatively correlated the } \\
\text { tendency to develop to asthma in children in human }\end{array}$ & {$[3]$} \\
\hline $\begin{array}{l}\text { The disturbance of gut microbiota in mice at } 3 \text { weeks of age was found to } \\
\text { increase the occurrence of allergic airway inflammation in adult mice }\end{array}$ & [8] \\
\hline $\begin{array}{l}\text { The transplantation of fecal microbiota can protect against the pneumonia in } \\
\text { microbiota-depleted mice }\end{array}$ & [10] \\
\hline $\begin{array}{l}\text { The metabolism of dietary fiber afforded by gut microbiota can influence the } \\
\text { extent of allergic inflammation in the airway in mice }\end{array}$ & [11] \\
\hline \multicolumn{2}{|l|}{ Lung-skin relationship } \\
\hline $\begin{array}{l}\text { The number and/or diversity of gut microbiota at birth is likely to be } \\
\text { positively associated with the pathogenesis of skin eczema in human }\end{array}$ & [2] [3] \\
\hline About $1 \%-2 \%$ patients with lung cancer may develop skin metastases & [13] \\
\hline $\begin{array}{l}\text { Elderly women with certain matrix metalloproteinase promotor variants } \\
\text { demonstrated a higher susceptibility to skin wrinkling and lung dysfunctions }\end{array}$ & [19] \\
\hline $\begin{array}{l}\text { About } 50 \% \text { infants who had acute severe bronchiolitis developed dry skin or } \\
\text { eczema within } 12 \text { months thereafter }\end{array}$ & [22] \\
\hline
\end{tabular}




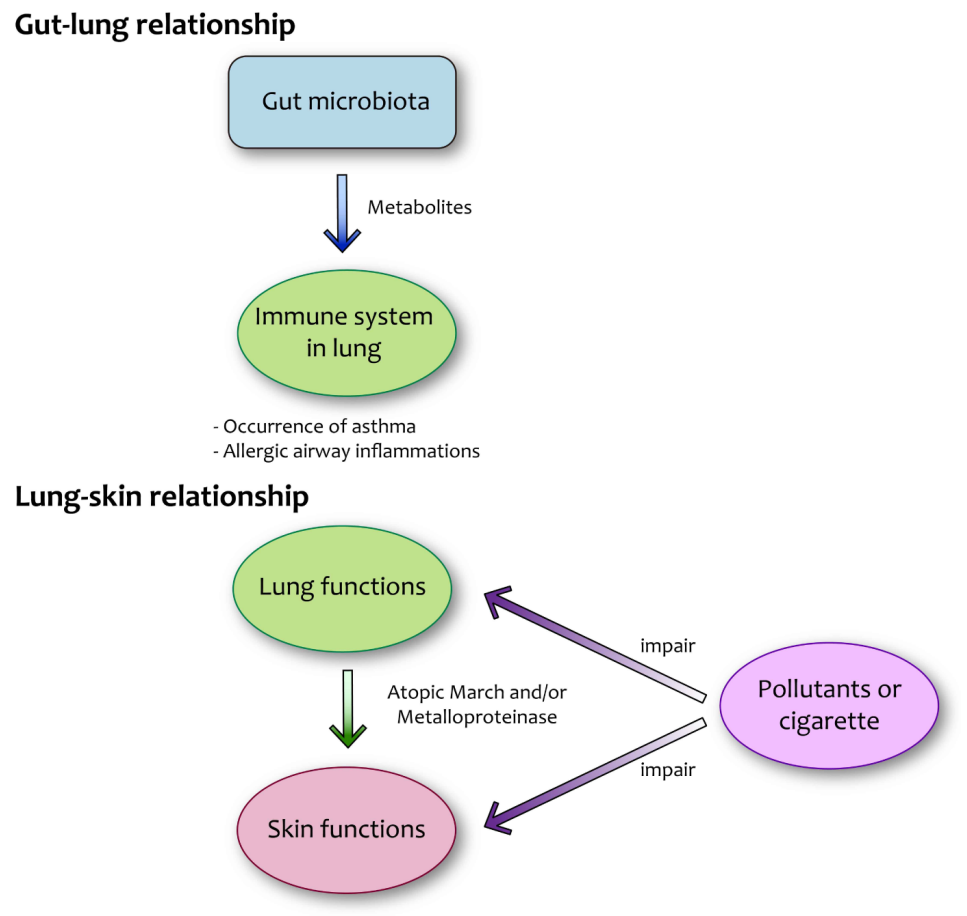

Figure 1. Summary of inter-organ relationships among gut, lung and skin.

organs through the intermediacy of signalling molecules. Certain questions arise: 1) to what extent can mucosal membranes communicate (given that there are many such epithelial cell layers inside the body in addition to those of the gut and the lungs)? 2) which organs are more susceptible to be influenced by others? and 3) what kinds of diseases have a stronger influence among different mucosal membranes.

The human body is comprised of multiple-organ systems. The organ axes, as discussed here, are likely to play a role, at least in part, in determining the function of the respective organs under normal and pathological conditions. Even in the practice of Chinese medicine, such inter-organ relationships are not used as the main guide for prescribing treatments. However, such understanding can arouse interest in investigating the etiology/pathogenesis of diseases beyond the organ of concern in modern medicine. Given the co-occurrence of certain diseases, therapeutic interventions should be targeted to organs that are functionally connected. This holistic approach in the prevention and/or treatment of diseases has long been adopted in Chinese medicine, but it is yet to be exploited in modern medicine.

\section{References}

[1] Bantz, S.K., Zhu, Z. and Zheng, T. (2014) The Atopic March: Progression from Atopic Dermatitis to Allergic Rhinitis and Asthma. Journal of Clinical and Cellular Immunology, 5, 202.

[2] Penders, J., Gerhold, K., Stobberingh, E.E., Thijs, C., Zimmermann, K., Lau, S. and Hamelmann, E. (2013) Establishment of the Intestinal Microbiota and Its 
Role for Atopic Dermatitis in Early Childhood. Journal of Allergy and Clinical Immunology, 132, 601-607. https://doi.org/10.1016/j.jaci.2013.05.043

[3] Abrahamsson, T.R., Jakobsson, H.E., Andersson, A.F., Björkstén, B., Engstrand, L. and Jenmalm MC. (2014) Low Gut Microbiota Diversity in Early Infancy Precedes Asthma at School Age. Clinical \& Experimental Allergy, 44, 842-850. https://doi.org/10.1111/cea.12253

[4] Shaykhiev, R. and Bals, R. (2007) Interactions between Epithelial Cells and Leukocytes in Immunity and Tissue Homeostasis. Journal of Leukocyte Biology, 82, 1-15. https://doi.org/10.1189/jlb.0207096

[5] Lozupone, C.A., Stombaugh, J.I., Gordon, J.I., Jansson, J.K. and Knight, R. (2012) Diversity, Stability and Resilience of the Human Gut Microbiota. Nature, 489, 220-230. https://doi.org/10.1038/nature11550

[6] Marsland, B.J., Trompette, A. and Gollwitzer, E.S. (2015) The Gut-Lung Axis in Respiratory Disease. Annals of the American Thoracic Society, 12, S150S156.

[7] Yang, F., Wang, J. and Wang Q. (2015) Allergic Diseases and Intestinal Flora Imbalance for Allergic Constitution Research. Journal of Beijing University of Traditional Chinese Medicine, 38, 509-514.

[8] Russell, S.L., Gold, M.J., Hartmann, M., Willing, B.P., Thorson, L., Wlodarska, M., Gill, N., Blanchet, M., Mohn, W.W., McNagny, K.M. and Finlay, B.B. (2012) Early Life Antibiotic-Driven Changes in Microbiota Enhance Susceptibility to Allergic Asthma. EMBO Reports, 13, 440-447.

https://doi.org/10.1038/embor.2012.32

[9] Nielsen, S., Needham, B., Leach, S.T., Day, A.S., Jaffe, A., Thomas, T. and Ooi, C.Y. (2016) Disrupted Progression of the Intestinal Microbiota with Age in Children with Cystic Fibrosis. Scientific Reports, 6, 24857. https://doi.org/10.1038/srep24857

[10] Schuijt, T.J., Lankelma, J.M., Scicluna, B.P., de Sousa e Melo, F., Roelofs, J.J., de Boer, J.D., Hoogendijk, A.J., de Beer, R., de Vos, A., Belzer, C., de Vos, W.M., van der Poll, T. and Wiersinga, W.J. (2016) The Gut Microbiota Plays a Protective Role in the Host Defense against Pneumococcal Pneumonia. Gut, 65, 575-583. https://doi.org/10.1136/gutjnl-2015-309728

[11] Trompette, A., Gollwitzer, E.S., Yadava, K., Sichelstiel, A.K., Sprenger, N., Ngom-Bru, C., Blanchard, C., Junt, T., Nicod, L.P., Harris, N.L. and Marsland, B.J. (2014) Gut Microbiota Metabolism of Dietary Fiber Influences Allergic Airway Disease and Hematopoiesis. Nature Medicine, 20, 159-166. https://doi.org/10.1038/nm.3444

[12] Kumar, M., Prasad, S.K. and Hemalatha, S. (2014) A Current Update on the Phytopharmacological Aspects of Houttuynia Cordata Thunb. Pharmacognosy Reviews, 8, 22-35. https://doi.org/10.4103/0973-7847.125525

[13] Mollet, T.W., Garcia, C.A. and Koester, G. (2009) Skin Metastases from Lung Cancer. Dermatol Online J, 15, 1.

[14] Frankel, A., Penrose, C. and Emer, J. (2009) A Practical Case Report and Review for the Dermatologist. J Clin Aesthet Dermatol, 2, 19-27.

[15] Hüls, A., Vierkötter, A., Gao, W., Krämer, U., Yang, Y., Ding, A., Stolz, S., Matsui, M., Kan, H., Wang, S., Jin, L., Krutmann, J. and Schikowski, T. (2016) Traffic-Related Air Pollution Contributes to Development of Facial Lentigines: Further Epidemiological Evidence from Caucasians and Asians. Journal of Investigative Dermatology, 136, 1053-1056. 
https://doi.org/10.1016/j.jid.2015.12.045

[16] Adam, M., Schikowski, T., Carsin, A.E., Cai, Y., Jacquemin, B., Sanchez, M., Vierkötter, A., Marcon, A., Keidel, D., Sugiri, D., Al Kanani, Z., Nadif, R., Siroux, V., Hardy, R., Kuh, D., Rochat, T., Bridevaux, P.O., Eeftens, M., Tsai, M.Y., Villani, S., Phuleria, H.C., Birk, M., Cyrys, J., Cirach, M., de Nazelle, A., Nieuwenhuijsen, M.J., Forsberg, B., de Hoogh, K., Declerq, C., Bono, R., Piccioni, P., Quass, U., Heinrich, J., Jarvis, D., Pin, I., Beelen, R., Hoek, G., Brunekreef, B., Schindler, C., Sunyer, J., Krämer, U., Kauffmann, F., Hansell, A.L., Künzli, N. and Probst-Hensch, N. (2015) Adult Lung Function and Long-Term Air Pollution Exposure. ESCAPE: A Multicentre Cohort Study and Meta-Analysis. European Respiratory Journal, 45, 38-50.

https://doi.org/10.1183/09031936.00130014

[17] Chang, A.L. (2016) Expanding Our Understanding of Human Skin Aging. Journal of Investigative Dermatology, 136, 897-899. https://doi.org/10.1016/j.jid.2016.02.020

[18] Vierkötter, A., Schikowski, T., Ranft, U., Sugiri, D., Matsui, M., Krämer, U. and Krutmann, J. (2010) Airborne Particle Exposure and Extrinsic Skin Aging. Journal of Investigative Dermatology, 130, 2719-2726. https://doi.org/10.1038/jid.2010.204

[19] Vierkötter, A., Schikowski, T., Sugiri, D., Matsui, M.S., Krämer, U. and Krutmann, J. (2015) MMP-1 and -3 Promoter Variants Are Indicative of a Common Susceptibility for Skin and Lung Aging: Results from a Cohort of Elderly Women (SALIA). Journal of Investigative Dermatology, 135, 1268-1274. https://doi.org/10.1038/jid.2015.7

[20] Elander, N., Söderkvist, P. and Fransén, K. (2006) Matrix Metalloproteinase (MMP) -1, -2, -3 and -9 Promoter Polymorphisms in Colorectal Cancer. Anticancer Research, 26, 791-795.

[21] Woo, M., Park, K., Nam, J. and Kim, J.C. (2007) Clinical Implications of Matrix Metalloproteinase-1, -3, -7, -9, -12, and Plasminogen Activator Inhibitor-1 Gene Polymorphisms in Colorectal Cancer. Journal of Gastroenterology and Hepatology, 22, 1064-1070. https://doi.org/10.1111/j.1440-1746.2006.04424.x

[22] Stokes, G.M., Milner, A.D., Hodges, I.G. and Groggins, R.C. (1981) Lung Function Abnormalities after Acute Bronchiolitis. The Journal of Pediatrics, 98, 871-874. https://doi.org/10.1016/S0022-3476(81)80577-X

[23] Böhme, M., Lannerö, E., Wickman, M., Nordvall, S.L. and Wahlgren, C.F. (2002) Atopic Dermatitis and Concomitant Disease Patterns in Children up to Two Years of Age. Acta Dermato-Venereologica, 82, 98-103. https://doi.org/10.1080/00015550252948112

[24] O'Neill, C.A., Monteleone, G., McLaughlin, J.T. and Paus, R. (2016) The Gut-Skin Axis in Health and Disease: A Paradigm with Therapeutic Implications. BioEssays, 38, 1167-1176. https://doi.org/10.1002/bies.201600008

[25] Marrs, T. and Flohr, C. (2016) The Role of Skin and Gut Microbiota in the Development of Atopic Eczema. British Journal of Dermatology, 2, 13-18. https://doi.org/10.1111/bjd.14907 
Submit or recommend next manuscript to SCIRP and we will provide best service for you:

Accepting pre-submission inquiries through Email, Facebook, LinkedIn, Twitter, etc. A wide selection of journals (inclusive of 9 subjects, more than 200 journals)

Providing 24-hour high-quality service

User-friendly online submission system

Fair and swift peer-review system

Efficient typesetting and proofreading procedure

Display of the result of downloads and visits, as well as the number of cited articles Maximum dissemination of your research work

Submit your manuscript at: http://papersubmission.scirp.org/

Or contact cm@scirp.org 